\title{
Free Radical Scavenging Capacity and Antibacterial Activity of Wild Cirsium creticum from Turkey
}

\author{
Temine Sabudak, Dumrul Gulen², H.Hulya Orak ${ }^{*}$, Merve Ozer ${ }^{1}$, Hilmican Caliskan ${ }^{1}$, Evren Cabi ${ }^{4}$ \\ ${ }^{1}$ Department of Chemistry, Faculty of Science and Arts, Namik Kemal University, Tekirdag, TURKEY. \\ 2Department of Medical Microbiology School of Medicine, Namik Kemal University, Tekirdag, TURKEY. \\ ${ }^{3}$ Department of Food Technology, Vocational School of Technical Sciences, Namik Kemal Un, Tekirdag, TURKEY. \\ ${ }^{4}$ Department of Biology, Faculty of Science and Arts, Namik Kemal University, Tekirdag, TURKEY.
}

\begin{abstract}
Background: In recent years, there is increasing interest the using of herbal extracts derived from plants in medicine and as a dietary supplements. Objective: We aimed the determination of the antioxidant and antibacterial activity of Cirsium creticum (Lam) d'Urv. subsp. creticum included Asteraceae family which is wild plant species in Trakya region. Methods: Crude $\mathrm{n}$-hexane, diethyl ether, ethylacetate and methanol extracts from whole plants was used the determination of antiradical and antibacterial activity in $C$. creticum and compared in terms of extracts efficiency. Results: EC $_{50}$ values of DPPH activity in different solvents revealed significant differences similar to TPC content. The lowest inhibitory effect was found to be Gram negative for $E$. coli, despite the highest inhibitory effect against Gram positive $S$. aureus. Conclusion: Antiradical and antimicrobial activity results presented that $C$. creticum, could be evaluate in food supplements and pharmaceutical industry as natural compound, and future investigations will be aimed the isolations of biologically active compounds to define individual active components.
\end{abstract}

Key words: Cirsium creticum, Antiradical activity, Antimicrobial activity, E. coli, S. aureus.

\section{INTRODUCTION}

The role of the free radicals and the reactive oxygen species (ROS) in the pathogenesis of human diseases, including cancer, aging, atherosclerosis, neurological damage, has been recognized. Antioxidants, are vital substances which possess the ability to protect the body from possible harms caused by the free radical induced oxidative stress which damage the cells in our bodies. ${ }^{1} \mathrm{~A}$ balance between free radicals and antioxidants is necessary for proper physiological function. ${ }^{2}$ If the free radicals overwhelm the body's ability to regulate them, a condition known as oxidative stress ensues. ${ }^{3}$

It is known that many taxa, belonging to the genus Cirsium Mill. (Koygocuren), have gained a rising interest in scientific area due to some pharmacologic activities. Generally, Cirsium seeds, stems and flowers have been used for the treatment of some illnesses such as varicose veins, haemorrhoids, peptic ulcer, cough and bronchitis and as remedy against mushroom poisoning as traditionally. ${ }^{4-6}$ An ethnobotanical study on useful and edible plants reported that peeling stems of $C$. creticum can be eaten as raw vegetable or cooked. ${ }^{7}$ C. creticum (Asteraceae) which is wild plant species in Trakya region of Turkey. In the literature there is no study on the biological activity of C. creticum plants. In this study, firstly, total phenolic content, antiradical activity and antimicrobial activity of the C. creticum which is wild plant species in Trakya region have been examined. The extracts of the C. creticum with high biological activity will be selected for isolation studies. Therefore, this will be a distinctive study in terms of its being the first in the literature.
DOI: 10.5530/ijper.51.3s.47 Correspondence: H. Hakime Hulya Orak, Department of Food Technology, Vocational School of Technical Sciences, Namik Kemal Un., Tekirdag, TURKEY

Phone no: +90 282 2504005; Fax: +90 2822509934 . Email Id: horak@nku.edu.tr; 


\section{MATERIALS \& METHODS}

\section{Plant material and extractions}

C. creticum which is wild plant species in Trakya region, was collected in June 2016. The specimens (NGBB 7230) were identified by Dr. Cabi at Namik Kemal University, Faculty of Science, Department of Biology. Air dried samples were used for $n$-hexane, diethyl ether, EtOAc, $\mathrm{MeOH}$ solvent extractions. The extractions were repeated two times, supernatants were combined, and solvents were evaporated under vacuum using a rotary evaporator.

\section{Total phenolics content (TPC)}

The total phenolic content (TPC) in plant extracts was determined by a colorimetric method with Folin \& Ciocalteu's phenol (FCP) reagent. ${ }^{8}$ Absorbance of supernatants was recorded at $725 \mathrm{~nm}$ (Hitachi UV/Vis). Total phenolic content was expressed as mg catechol equivalents (CAE).

\section{Antiradical activity against DPPH'}

The scavenging effect of free radical scavenging was assayed by DPPH (2,2-diphenyl-1picrylhydrazyl ) method against DPPH radical was monitored at $517 \mathrm{~nm}$ as described by Amarowicz et al. (2002). ${ }^{9}$

\section{Determination of the antibacterial activity}

The antibacterial activity was tested against four bacteria strains, which were Staphylococcus aureus (ATCC 43300), Escherichia coli (ATCC 35218), Bacillus subtilis (NRRL NRS-744) and Pseudomonas aeruginosa (ATCC 27853). Bacterial suspensions in the logarithmic growth phase were diluted according to the McFarland 0.5 turbidity standard in Mueller-Hinton Broth and then $100 \mu \mathrm{l}$ from this suspension spread to agar plate surface plate. Plant extracts were solved in $1 \mathrm{ml}$ water and $100 \mu \mathrm{l}$ added to each well which were opened on the surface of the agar. Gram positive bacteria Penicillin $(10 \mathrm{IU} / \mathrm{ml})$ and for the other bacteria Gentamicin (10 $\mathrm{g} / \mathrm{ml})$ are tested as control. Zone diameters are measured after $37^{\circ} \mathrm{C}$ incubation.

\section{RESULTS \& DISCUSSION}

\section{Total phenolic content (TPC)}

TPC of C. creticum extracts ranged between $1.33 \mathrm{mg}$ $\mathrm{CAE} / \mathrm{g}$ and $47.90 \mathrm{mg} \mathrm{CAE} / \mathrm{g}$ extract. The highest TPC value was found in methanolic extract of $C$. creticum (47.90 mg CAE/g) (Table 1). Our findings was similar to Nazaruk et al. $(2008)^{10}$ results, who determined the different Cirsium species TPC between 43.73 and 178.27 $\mathrm{mg} / \mathrm{g}$. As shown in Figure 1, DPPH radical scavenging activities of extracts were concentration dependent

\begin{tabular}{|c|c|c|}
\hline \multicolumn{3}{|c|}{$\begin{array}{c}\text { Table 1: Total Phenolic Content and } \text { EC }_{50} \text { values of } \\
\text { DPPH activity of } \boldsymbol{C} \text {. creticum extracts }\end{array}$} \\
\hline Extract & $\begin{array}{c}\text { Total Phenolic content } \\
(\boldsymbol{\mu} \text { catechol Eq } / \mathrm{mg} \\
\text { extract) }\end{array}$ & $\begin{array}{c}\mathrm{EC}_{50}{ }^{*} \\
\text { values of } \mathrm{DPPH} \\
\text { activity }\end{array}$ \\
\hline $\mathrm{MeOH}$ & $47.90 \pm 0,49$ & $0.24 \mathrm{mg} /$ assay \\
\hline EtOAc & $15.29 \pm 1.82$ & $1.42 \mathrm{mg} /$ assay \\
\hline Diethyl Ether & $19.55 \pm 0.16$ & $1.71 \mathrm{mg} /$ assay \\
\hline n-hexane & $1.33 \pm 0.04$ & $2.05 \mathrm{mg} /$ assay \\
\hline
\end{tabular}

*The EC 50 value, defined as the amount of antioxidant necessary to inactivate $50 \%$ of initial DPPH•, was estimated based on the plot.

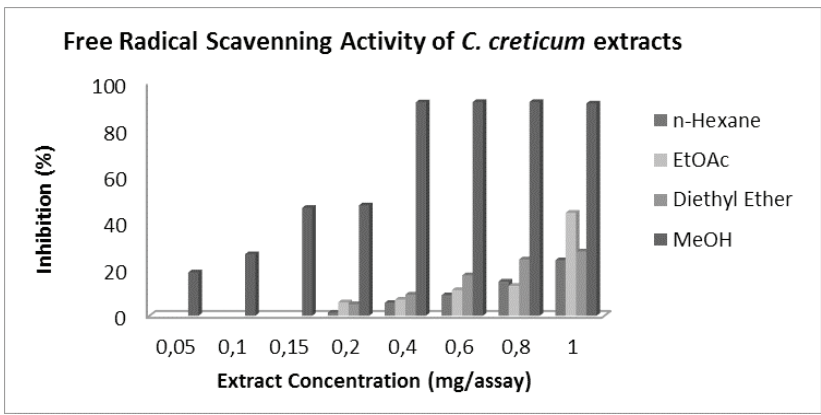

Figure 1: DPPH radical scavenging activity of $C$. creticum extracts.

and methanol extracts showed the highest activities (91.65\%). DPPH activities of hexane, ethyl acetate, diethyl ether and extracts was determined as $5.53 \%$, $6.93 \%, 9.11 \%$ at the same concentration respectively.

$\mathrm{EC}_{50}$ values of DPPH activity in different solvents revealed significant differences similar to TPC content. This could be due to the differences in extractability of different solvents and it may be due to poor solubility of phenolics of this plant in hexane. These results in confirmed with the earlier researches that reported the solvent with methanolic extract showing relatively higher antioxidant ability. ${ }^{11}$ This could probably be because of their higher polarity and betters solubility for phenolic components present in plant materials.

\section{Antibacterial Activity}

In recent years, many types of microorganisms with active infectious diseases have become resistant to antibiotics and also, for most of uses because of high toxic effect of antimicrobial drugs it is limited. According to Table 2, the lowest inhibitory effect was found to be Gram negative for E. coli (ATCC 35218), despite the highest inhibitory effect against Gram positive S. aureus (ATCC 43300). However, plant extracts showed antimicrobial activity against Pseudomonas aeruginosa close to Gentamicin. Karou et al. $(2012)^{12}$ revealed that E. coli CIP 105182, which was found to be the most resistant 
Table 2: Antibacterial activity of C. creticum

\begin{tabular}{|c|c|c|c|}
\hline Bacteria & $\begin{array}{c}\text { Extract } \\
\text { zone }\end{array}$ & Penicilin & Gentamicin \\
\hline Staphylococcus aureus & $21 \mathrm{~mm}$ & $33 \mathrm{~mm}$ & - \\
\hline Bacillus subtilis & $17 \mathrm{~mm}$ & $30 \mathrm{~mm}$ & - \\
\hline Escherichia coli & $13 \mathrm{~mm}$ & - & $17 \mathrm{~mm}$ \\
\hline $\begin{array}{c}\text { Pseudomonas } \\
\text { aeruginosa }\end{array}$ & $14 \mathrm{~mm}$ & - & $15 \mathrm{~mm}$ \\
\hline
\end{tabular}

bacterial strain and was only inhibited by $S$. longepedunculata among five medicinal plant extracts.

\section{CONCLUSION}

Results presented that future investigations will be aimed the isolations of biologically active compounds such as flavonoids from C. creticum, as natural compounds for evaluation in pharmaceutical industry. Because of their antimicrobial activity they can be used as topical preparation or by food preservation.

\section{ACKNOWLEDGMENT}

We would like to thank TUBITAK for financial support of the project (116Z450).

\section{CONFLICT OF INTEREST}

None

\section{ABBREVIATION USED}

$\mathrm{EC}_{50}$ : The amount of antioxidant necessary to inactivate $50 \%$ of initial DPPH; DPPH: 2,2-diphenyl-1picryl- hydrazyl; TPC: Total phenolic content; ROS: Reactive oxygen species; EtOAc: Ethyl acetate; MeOH: Methanol ; FCP: Folin \& Ciocalteu's phenol reagent; CAE: Catechol Equivalents.

\section{REFERENCES}

1. Patel S, Gokhale M. Comparative Study of Antioxidant Activity of Ethanol and Aqueous Extracts of Different Parts of Nyctanthes Arbor-tristis Linn. Pharmacogn J. 2016;8(2):113-6.

2. Lobo V, Patil A, Phatak A, Chandra N. Free radicals, antioxidants and functional foods: Impact on human health. Phcog Rev. 2010;4(8):118-26.

3. Shiromwar SS, Chidrawar VR. Combined effects of $p$-coumaric acid and naringenin against doxorubicin-induced cardiotoxicity in rats. Phcog Res. 2011;3(3):214-9.

4. Loizzo MR, Statti GA, Tundis R, Conforti F, Ando S, Menichini F. Antimicrobial activity and cytotoxicity of Cirsium tenoreanum. Fitoterapia. 2004;75(6):577-80.

5. Orhan DD, Ergun F, Yesilada E, Tsuchiya K, Takaishi Y, Kawazoe K. Antioxidant activity of two flavonol glycosides from Cirsium hypoleucum DC. Through bioassay-guided fractionation. Turkish J Pharmaceut Sci. 2007;4(1):1-14.

6. Jain S, Dwivedi J, Jain PK, Satpathy S, Patra A. Medicinal Plants for Treatment of Cancer. A Brief Review. Pharmacogn J. 2016;8(2):87-102.

7. Kızılarslan $\mathrm{C}$, Ozhatay N. An ethnobotanical study of the useful and edible plants of İmit. Marmara Pharm J. 2012;16(3):134-40.

8. Amarowicz R, Karamać M, Kmita-Głażewska H, Troszyńska A, Kozłowska H. Antioxidant activity of phenolic fractions of everlasting pea, faba bean and broad bean. J. Food Lipids. 1996;3(3):199-211.

9. Amarowicz R, Karamać M, Weidner S, Abe S, Shahidi F. Antioxidant activity of wheat caryopses and embryos extracts. J Food Lipids. 2002;9(3):201-10.

10. Nazaruk J, Czechowska SK, Markiewicz R, Borawska MH. Polyphenolic compounds and in vitro antimicrobial and antioxidant activity of aqueous extracts from leaves of some Cirsium species. Nat Prod Res 2008;22(18):1583-8.

11. Zhao M, Yang B, Wang J, Li B, Jiang Y. Identification of the majör flavonoids from pericarptissues of lychee fruit in relation to their antioxidant activities. Food Chem. 2006;98(3):539-44.

12. Karou SD, Tchacondo T, Tchibozo MAD, Anani K, Ouattara L, Simpore J, et al. Screening Togolese medicinal plants for few pharmacological properties. Pharmacogn Res. 2012;4(2):116-22.

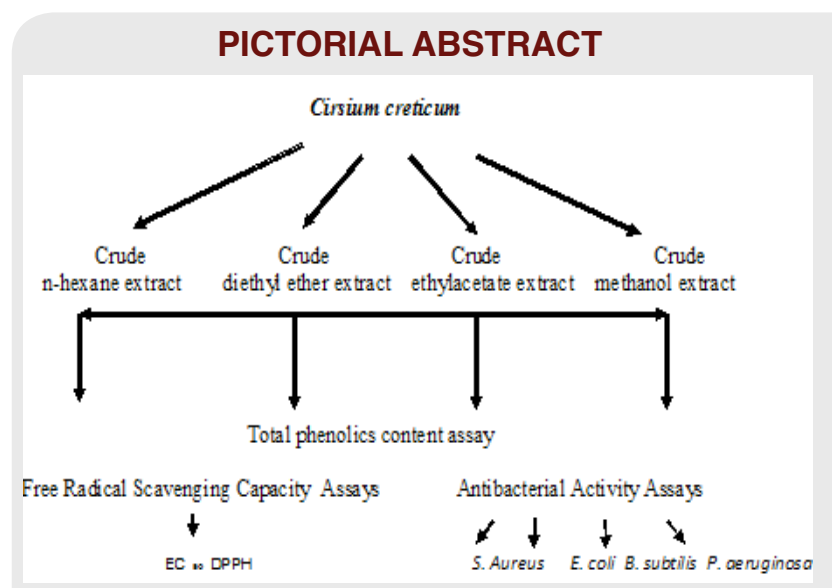

\section{SUMMARY}

- Cirsium creticum (Asteraceae) is wild plant species.

- Crude extracts of plants obtained n-hexane, ether, EtOAc, $\mathrm{MeOH}$ extraction methods.

- The content of total phenolic was determined using Folin \& Ciocalteu's phenol reagent and free radical scavenging activity was assayed by DPPH method.

- The antibacterial activity was determined against four bacteria strains, which were Staphylococcus aureus, Escherichia coli, Bacillus subtilis and Pseudomonasa eruginosa

- It is presented that C. creticum can be used as as natural compounds for evaluation in pharmaceutical industry or by food preservation . 


\section{ABOUT AUTHORS}

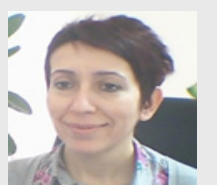

Temine Sabudak: Professor at Department of Chemistry, Faculty of Art and Sciences, University of Namik Kemal in Turkey. She is working on the chromatographic separation, purification and determination of chemical structures of organic compounds from natural products. Additionally her expert area is orgnic synthesis, spectroscopy phytochemistry.

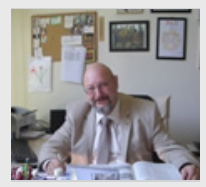

Dumrul GULEN: Associate Professor Namık Kemal University School of Medicine Department of Medical Microbiology, Head of Tumor Biology \& Immunology Department Institute of Health Sciences, Editor of Journal of Hematology And Oncology Research (JHOR). Specific interests are Tumor immunotherapy, Tumor immunology, Investigation of antibacterial, antifungal, antitumoral effects of plant-derived substances

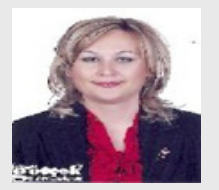

H. Hulya Orak: Associate Professor at Department of Food Tecnology, University of Namik Kemal in Turkey. She is interested in antioxidant activities of fruits, legumes, some plant materials and medical plants. Additionally her expert area is enzyme activities, drying and freezing technology of vegetables and fruits.

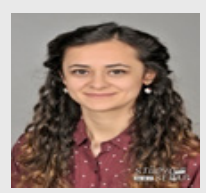

Merve Ozer: She is continuing her MSc at Department of Chemistry, Faculty of Science and Arts at Namik Kemal University and she is member of the Project of Tubitak (116Z450).

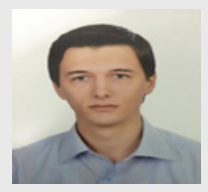

Hilmican Caliskan: He is continuing his MSc at Department of Chemistry, Faculty of Science and Arts at Namik Kemal University and he is member of the Project of Tubitak (116Z450).

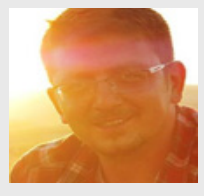

Evren Cabi: Associate Professor at Department of Biology, Namık Kemal University Faculty of Art and Sciences. His areas of research interest include 'Plant Systematics and Phylogeny', 'Ecology' and Conservational Biology'. He is author of over 100 peer-reviewed publications and 1 book chapter and 1 book. He collected the plant material from the natural flora of Turkey and identified them for this study

Cite this article: Sabudak T, Gulen D, Orak HH, Ozer M, Caliskan H, Cabi E. Free Radical Scavenging Capacity and Antibacterial Activity of Wild Cirsium creticum from Turkey. Indian J of Pharmaceutical Education and Research. 2017;51(3)Suppl:S359-62. 